\title{
Solar Power-Operated Microcontroller-Based Earthquake Detector with Automatic Alarm System
}

\author{
Mark Jayron G. Galang ${ }^{1}$, Jay Ar F. Felia ${ }^{2}$, Mark June T Fajutnao ${ }^{3}$, Carl Lyle Cezar C. Felia ${ }^{4}$, \\ Dr. Paquito G. Fernando Jr ${ }^{5}$ \\ ${ }^{1}$ John Paul College, Philippines, jayronmj@gmail.com \\ ${ }^{2}$ John Paul College, Philippines, jayarfelia01@ gmail.com \\ ${ }_{3}^{3}$ John Paul College, Philippines, marcfajutnao@gmail.com \\ ${ }^{4}$ John Paul College, Philippines, lylelafelia@ gmail.com \\ ${ }_{5}^{5}$ John Paul College- Computer Engineering Department, Philippines, kitzfernando@gmail.com
}

\begin{abstract}
This study shows the development of an earthquake detector unit system using Arduino Mega and ADXL335 accelerometer. The alarm system will be triggered and will give a sound when the microcontroller-based earthquake detector detects a ground motion of specified intensity levels. A solar panel system is also integrated to the unit to provide its own generated electric current to supply power to the whole system. Having a solar power-operated earthquake detector with automatic alarm system will help in raising awareness about the occurrence of earthquakes to minimize the number of physical harms to humans and accidents.
\end{abstract}

The project was developed using the following steps namely: Problem Identification, Research, Requirements Specification, Concept Generation, Design, Prototype and Construct, System Integration, System Test, and Evaluation.

Key words: Earthquake, Earthquake Detector, Earthquake Alarm System, Arduino Mega, ADXL335 accelerometer.

\section{INTRODUCTION}

An earthquake is a detectable shaking of the Earth's surface due to the abrupt release of energy from the Earth's crust that generates seismic waves. It can cause damage to manmade structures in addition to leaving an impression to the environment. It can also be harmful to human being especially when people are not aware enough of the things they should do to become safe.[1] There are different causes and types of earthquake: the inter plate earthquake, intraplate earthquake, foreshocks and aftershocks, volcanic activity, and human-induced earthquakes and other seismic events. Inter plate earthquakes are earthquakes that occur along the boundary of the tectonic plate. Intraplate earthquakes occur in the interior of the plate, away from the edges of the plate. Intraplate earthquakes are not as common as those on the edges of the plate, and are usually not as large as interpolate earthquakes. Foreshocks are smaller earthquakes that may occur prior to a major earthquake or a main shock and are caused by the fracture of the rocks under stress, while aftershocks are smaller earthquakes that may occur after a major shock. They are caused by rocks in the area that are readjusting to the fault movement, and some may be the result of continuing to move along the same fault. Volcanic tremors happen when magma collects in a high level reservoir before a volcanic eruption and as it moves around it causes bursts of continuous vibration. Explosions used to tunnel through rocks, dig open pit mines, and break up ore cause seismic waves. The removal of material during some mining processes leaves voids behind, which may unbalance existing stress in the surrounding rocks, causing small local earthquakes as the rocks settle into a new equilibrium. Landslides and gradual mass movements of large volumes of soil and rock may be large enough to be felt as earthquakes or as a sustained disruption of the soil. Meteorites cause seismic waves to radiate from the point of impact on the surface of the Earth, which can be registered or felt at a distance like a small earthquake. Meteors that explode high in Earth's atmosphere can produce large waves of sound which can shake the ground and look like small earthquakes.[2]

In the Philippines, an average of 20 earthquakes per day can be experienced (most are too weak to be felt).[3] The deadliest recorded earthquake in the country since $1600 \mathrm{~s}$ is the 8.0 magnitude tectonic earthquake in Moro Gulf, Mindanao on August 16, 1976 which killed 4,791 lives. Technologies of the modern generation enable seismic monitoring equipment to develop into early warning systems for earthquake, capable of decreasing fatalities, accidents, and financial losses, as well as accelerating rescue reaction and restoration of harm.[4]

During the shaking of the Earth caused by an earthquake, some people, especially those who are not very much aware of the right practices to do during and after an earthquake, usually run away out of a building where they are in at the moment an earthquake occurs. In some cases, some 
Mark Jayron G. Galang et al., International Journal of Information Technology Infrastructure , 9(4), July - August 2020,10 - 15

people do not actually feel the Earth's ground movement especially when the earthquake is at a low intensity and people are too busy with their works or when noise level in a particular area is high. With this matter, it is not advisable to stand, walk, or run during the shaking because people may get dizzy which may lead to serious harm to the head and body. People who are indoors have to stay indoors until the shaking stops and do the duck-cover-hold practice when they first feel the movement and stay on that position until it is safe to leave. Also, when people are inside a room or a building with high volume of sound or noise, low-level earthquake intensities are sometimes unfelt.

According to Mr. Ishmael C. Narag, the Supervising Science Research Specialist - Officer in Charge of the Seismological Observation and Earthquake Prediction Division, PHIVOLCS-DOST, power outages normally occur during large earthquakes and may persist until the power is restored by the utility company, which may affect the functionality of the device system in the event of a blackout. From the title of this study, this will tackle the power budget issue using a set of solar panels and batteries. The system will have the ability to produce its own electrical energy.

\section{REVIEW OF EXISTING WORKS}

According to a study of A. Trnkoczy, P. Bormann, W. Hanka, L. G. Holcomb, and R. L. Nigbor[5], Weak-motion records made with seismometers installed close to the epicenter will be clipped during most damaging earthquakes. Seismometers are particularly sensitive to small and distant events, and are therefore very sensitive to signals of heavy motion. At the time of analog recordings, that was a very relevant aspect. Accelerometers have traditionally been considered only for strong motion, and seismometers for weak motion. Nevertheless, the latest generation accelerometers are almost as sensitive as standard short-period (SP) seismometers down to frequencies around $1 \mathrm{~Hz}$ and also have a large dynamic range. Consequently, accelerometers will perform just as well as $1-\mathrm{Hz}$ SP seismometers for most conventional SP networks, and they are priced similarly. Simultaneously, wireless devices are now more affordable and have wider dynamic range. Largeband seismometers may be adequate in areas where only moderate size earthquakes are predicted. However, their gain for higher frequencies $(>10$ $\mathrm{Hz})$ may be less than for SP sensors. As far as signal processing is concerned, there is no difference in the use of a seismometer or accelerometer and the correction of digital data for differences in instrument response can make the signals look identical.

In a study of V. G. A. Sharma[6], the ADXL335 accelerometer was used in the earthquake-prone connected to an Arduino Mega (ATMega 328), which is linked by a wireless network to the data centers. ADXL335 can sense movements from all directions X, Y, and Z. The ADXL335 is a low-power, full 3-axis accelerometer with signal-conditioned voltage outputs and can monitor static and dynamic accelerations. Controller programming is done using the Arduino 1.8.3 code to obtain seismic wave graphical information in $\mathrm{X}, \mathrm{Y}, \mathrm{Z}$ directions.

According to A. Nishanth and C. Vanmathi's[7] study, the accelerometer is used to track earthquakes and tsunamis. Since the system is highly sensitive and can trigger false alarms most of the time, the threshold range can be specified and set according to our convenience and at the same time does not compromise the performance. The Arduino microcontroller is used as the main component which communicates with several sensors to detect any unexpected changes that may lead to a disaster. In that case, the warning system is activated and sends a distress signal to the mobile user. Here, a highly sensitive accelerometer is used to read horizontal, vertical and z-dimensional waves from the earth. The threshold level must be set either manually or using pre-defined values and an alarm can be set if readings surpass the threshold level.

\section{PROPOSED SYSTEM}

To successfully develop and understand the system, many factors have been considered such as the design, the materials to be used, circuits and its analysis, block diagram, and process flow chart.

\subsection{COMPONENTS REQUIREMENTS}

Table 1: Hardware and Software Requirements

\begin{tabular}{|l|c|}
\hline \multicolumn{1}{|c|}{ H ardware } & Specifications \\
\hline Arduino board & Mega \\
\hline Accelerometer & ADXL335 \\
\hline LCD & $16 \times 2-$ LCD 1602 \\
\hline Buzzer & 20A 12V \\
\hline Photovoltaic Cells & 10A 12V Solar Charger \\
\hline Regulator & 12V Motorcycle Battery \\
\hline Battery & \\
\hline Breadboard & \\
\hline Potentiometer & IDE \\
\hline Software & Specification \\
\hline Arduino &
\end{tabular}

Table 1 shows the hardware and software requirements in the development of the proposed system.

The system is a combination of hardware and software components. Hardware components have different functions in the system, which are needed in the system's process, while software program and codes are used to make some hardware components function better.

The Arduino Mega board serves as the brain of the system. All other hardware components, except the solar panel system), are connected into it because the program in the Arduino board will command the other components as to when and how they will function. 
Mark Jayron G. Galang et al., International Journal of Information Technology Infrastructure , 9(4), July - August 2020,10 - 15

The ADXL335 accelerometer sensor is the one that is responsible for the detection of XYZ motions. When it detects ground motion that is equivalent to the value of motion in the Arduino program, the detected motion will be sent to the Arduino and may trigger an alarm when required value of motion is met.

The LCD's function in the system is to display printed scripts on the screen. It will display the status and the readings of the ADXL335 accelerometer sensor.

The buzzer or siren serves as the main output device. When the accelerometer sensor detects the required value or higher value of ground motion, the buzzer will be triggered and will give alarm sounds.

The Photovoltaic Cell is one of the main parts of the solar panel system. It is responsible for absorbing solar energy and converting it into electricity. The regulator is also a part of the solar panel system which is used to control the voltage transferred from solar panel to the battery. The Battery is used to store electric current which is used to supply electricity to the system.

A breadboard is also used to add space for other connections in order to prevent the wires in the Arduino board from becoming crowded. In this project, the pins of the potentiometer and the LCD are connected.

The Potentiometer is used in the system to adjust the brightness of the LCD.

The switch is for turning the device on or off. Arduino code is also uploaded to the Arduino Mega board with a program that will be used for the functionality of the hardware components.

\subsection{METHODOLOGY}

\section{A.BLOCK DIAGRAM}

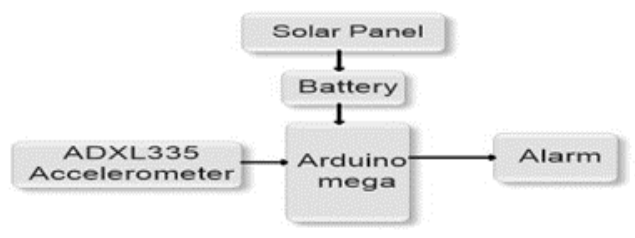

Figure 1: Block diagram

The illustration Fig. 1 is the block diagram of the hardware components that illustrates the connections of all system's hardware components. It shows that when electric current is produced by the solar panel by converting solar energy into electric energy, current will be stored in the battery which will be used to supply power to the Arduino Mega. The ADXL335 and Siren alarm are both connected to the Arduino Mega board.

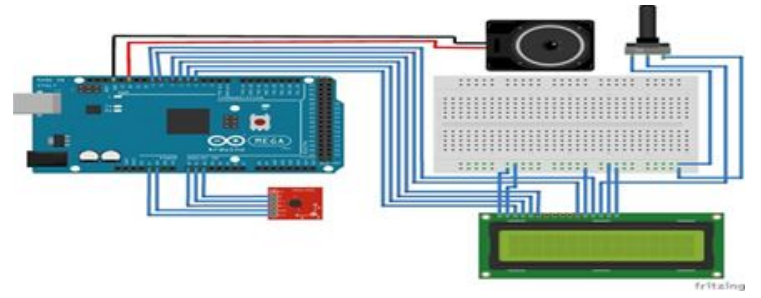

Figure 2: Circuit Diagram

Figure 2 shows the circuit diagram of the project design. The pins of the main components are connected to the Arduino Mega such as the ADXL335 accelerometer sensor, buzzer and LCD. In this project, a breadboard is used to connect the pins of the potentiometer and the LCD.

\section{B. Process ANd Flowchart}

Figure 3: Process Flowchart

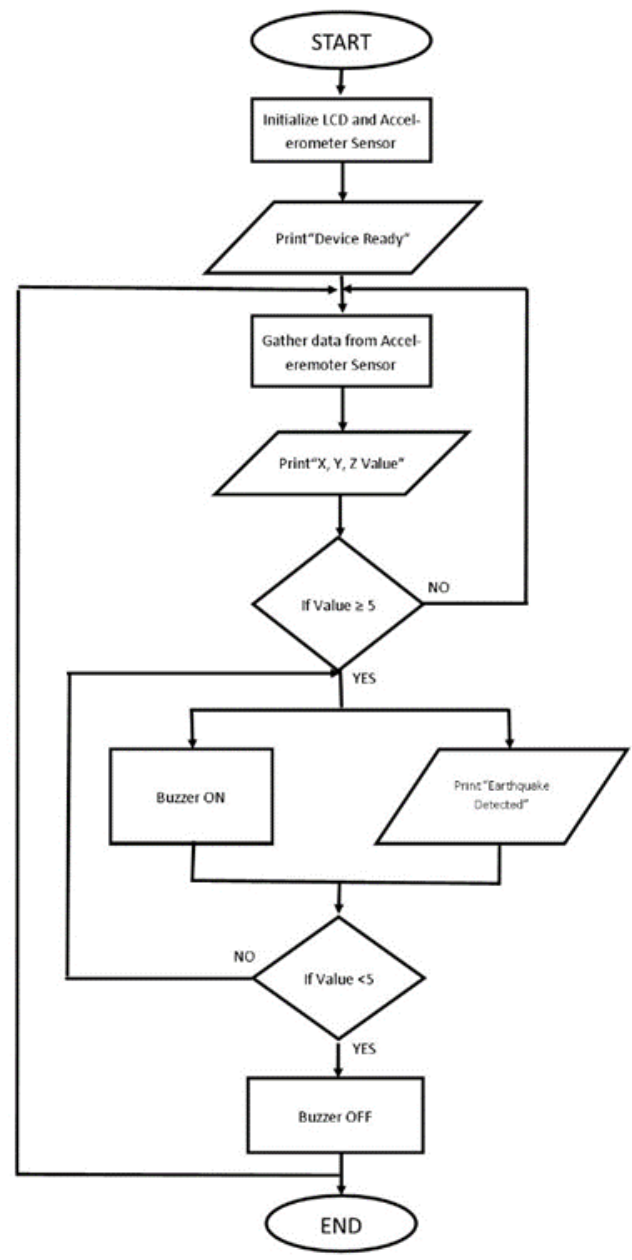

Figure 3 shows the process flowchart in the development of the proposed system. The Solar panel gets solar energy from sunlight and converts it into electrical energy which will pass through the regulator and will store the electricity in the battery. The electricity stored in the battery will supply the power to the system. 
When the device's switch is turned on, the accelerometer sensor will initialize reading the current data detected by the sensor then will display it on the LCD screen. When the sensor is ready, a script "Device Ready" will be printed on the LCD screen.

The sensor will start detecting ground movements. The ADXL335 accelerometer is responsible for the detection of accelerations. Once this sensor detects acceleration from 0.0017 to $0.014 \mathrm{~g}$, the system will give an alarm signal through the buzzer/siren.

\subsection{DESIGN}

The creation of an earthquake sensor with automatic alarm system could be very helpful to address such problem. Once the device detects an earthquake, the siren/buzzer will be triggered and will warn the people through a sound and will stop at the moment that there is no more underground movement being detected. When the alarm stops giving sounds, it means that it is now safe for people to evacuate the place and take preventive steps.

Figure 5: The Current Design of the Project

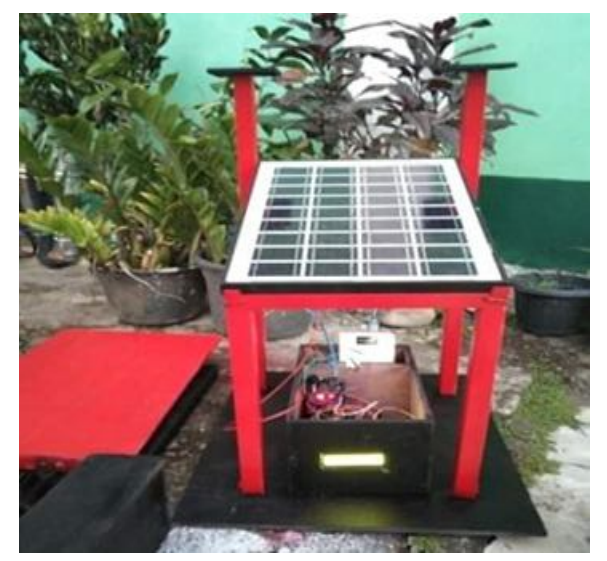

Figure 5 shows the current design of the project that was considered for the presentation purposes only. The project design is composed of three major parts which will function together as one as a solar powered earthquake detector with alarm system. In the actual application of the project, solar panels must be placed in the area where it will be able to get enough sunlight to keep the battery fully charged with electricity at all time. Buzzers can be placed in different areas where the sound alarm can be heard by the mass but may require longer wires.

\section{RESULTS AND DISCUSSION}

A solar power-operated microcontroller-based earthquake detector with automatic alarm system was developed. A number of twenty evaluators examined the project's reliability, functionality, durability, innovativeness, applicability, and sustainability to determine the points to maintain and improve. The pool of evaluators was composed of disaster risk officers, community leaders, establishment manager, IT, Computer, Engineering, and Science teachers, and civil engineering students.

Figure 4: Result of Evaluation (percentage)

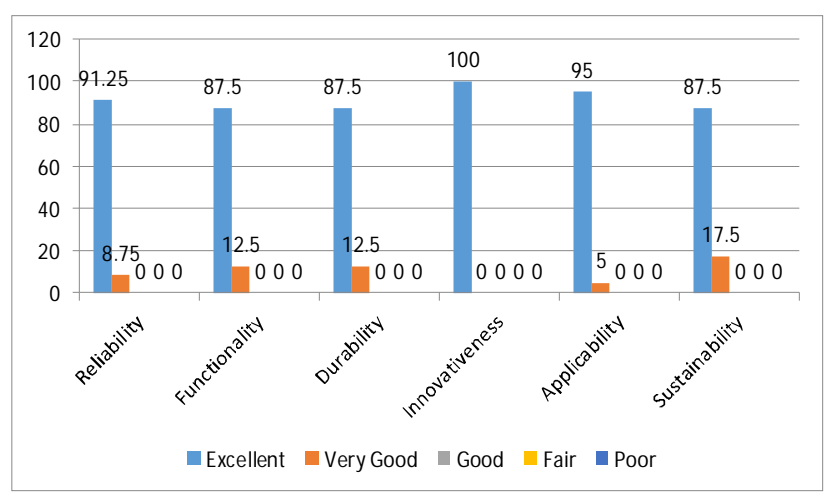

In Fig. 4, it shows that the project's reliability was rated Excellent by $91.25 \%$ of the respondents and Very Good by $8.75 \%$. It was tested that the sensor doesn't react to external noise such as vibrations due to strong thunder or heavy vehicles passing by, which may cause false triggers. False triggers may cause the community people not to trust the reliability of the device. It was also tested that the accelerometer sensor responds at real-time ground movement detection, and the system works consistently. The system can be a big contribution to disaster/earthquake preparedness plans.

The overall functionality of its parts was rated Excellent by $87.5 \%$ and Very Good by $12.5 \%$ of the respondents. The four major parts of the device, such as the (1) solar panel, (2) battery, (3) sensor, and (4) alarm, were tested and are functioning well. The $12 \mathrm{~V}$ solar panel is capable of generating electric energy. The $12 \mathrm{~V}$ battery can store enough electric energy to supply power to the system in order to operate even during power outages. The sensor detects ground movement and triggers the alarm. The sound of the alarm can reach a wide range of area.

The durability was rated Excellent by $87.5 \%$ and Very Good by $12.5 \%$. The durability was also tested to make sure that the device can stand and still continues to function even during a strong earthquake strike. It was ensured that the wirings and connections are organized and properly assembled in order to prevent device malfunctions. The microcontroller unit's case must also be durable because it protects the microcontroller and other components. 
The innovativeness was rated Excellent by $100 \%$ of the respondents. The integration of solar panel system adds innovation to the system. The project's applicability to communities and establishments was rated Excellent by $95 \%$ and Very Good by $5 \%$ of the respondents. Evaluators were asked if the device can be applicable for communities including the barangays and schools, for small establishments such as computer shops and restaurants, and for large establishments such as municipal halls and offices.

The sustainability was rated Excellent by $87.5 \%$ of the respondents and Very Good by $17.5 \%$. The project must be sustainable so that it can be used for a very long period of time. Common problems in sustaining the device were considered. In order to sustain it, the parts must be affordable and available in local stores, and that the community can perform the repairs and replacements of the parts for its maintenance.

\section{CONCLUSIONS}

The Solar Power-operated Microcontroller-based Earthquake Detector with Automatic Alarm System was developed using a microcontroller. The main parts of the system are the solar panel, microcontroller, sensor, and siren alarm. The project was developed to detect earthquakes and gave sound alarms as signal. The main output of the device is the sound alarm that it gives when an earthquake is detected. The system has its own electricity-generating system to provide power to the whole system. Working with ADXL335 using Arduino Mega to detect earthquakes is easy. Now that we have a microcontroller-based earthquake detector, it will need a power supply in order to operate. We can get power supply from different power sources, but for the efficiency of the project, we will integrate it with a solar panel system. Solar panel generates its own electric energy and then supplies electric power to the system. This will be helpful for the system in case of power outages before, during, or after the earthquake because it will continue to function.

\section{6.. RECOMMENDATION}

For future studies, some recommendations were made that can be used to add in the system.

1. GSM Module. A GSM Module is an electronic component that is used to allow the device to send data into mobile phones through SMS messaging. The use of GSM module is recommended for the purpose of monitoring.

2 Memory card module. It will allow the device to store up data into a memory card for the purposes of data gathering and record keeping. In this project, the solar panel and the buzzer are placed near the microcontroller for presentation purposes only.

Solar PVCs must be placed in an area where a good supply of sunlight is available. A longer wire will be needed to connect the photovoltaic cells to the regulator.
The microcontroller unit must be placed in a safe area where there are fewer factors that may affect the performance of the device, a place that is far away from highways where large vehicles may pass nearby.

\section{ACKNOWLEDGMENT}

The success of this study couldn't be possible without the persons who helped us from the beginning till end in different ways. We would like to thank the following people:

To our adviser, Dr. Kitz Fernando, whose encouragement, guidance and support from the initial to the final level enabled us to develop an understanding of the study. Without his guidance and persistent help, finishing this study would not have been easy.

To the respondents of the study, from the consultation to the evaluation phases, thank you. To Municipal Disaster Risk Reduction and Management Office of the Municipality of Mansalay, Mansalay Oriental Mindoro, for allowing one of our members to participate and volunteer once in their earthquake preparedness program in 2017, which became an inspiration to do the study, to help communities in becoming prepared for disasters like earthquakes. To Mr. Ishmael C. Narag, the Supervising Science Research Specialist - Officer in Charge of the Seismological Observation and Earthquake Prediction Division, PHIVOLCS-DOST, for answering our questions about the feasibility of the project and also for giving some tips and points to consider in doing the project. To the evaluators, who helped us in determining the high and low points of the project/study for improvements, thank you very much. Also, we would like to acknowledge the efforts of our classmates for the shared knowledge that helped us in finishing the study. Lastly, we would not forget most especially our beloved parents who work hard to financially support our project and give us the best education we can have.

\section{REFERENCES}

[1] S. Seemeen and V. Durga, "Effects of the mortuary on the surrounding environment," Indian J. Forensic Med. Toxicol., vol. 12, no. 4, pp. 60-64, 2018, doi: 10.5958/0973-9130.2018.00196.2.

[2] G. Lewis, "Earthquakes- Teacher notes and student activities." 2014.

[3] A. D. Orallo, "Study on earthquake risk and vulnerability management and lessons learned," no. October, pp. 1-67, 2011.

[4] C. Satriano, Y. M. Wu, A. Zollo, and H. Kanamori, "Earthquake early warning: Concepts, methods and physical grounds," Soil Dyn. Earthq. Eng., vol. 31, no. 2, pp. 106-118, 2011, doi: 10.1016/j.soildyn.2010.07.007.

[5] A. Trnkoczy, P. Bormann, W. Hanka, L. G. Holcomb, and R. L. Nigbor, “of Seismic Stations," pp. 1-108. 
Mark Jayron G. Galang et al., International Journal of Information Technology Infrastructure , 9(4), July - August 2020,10 - 15

[6] V. G. A. Sharma, "Prediction of Earthquake Using 3 Axis Accelerometer Sensor (ADXL335) and Arduino Uno," Int. J. Sci. Res., vol. 6, no. 9, pp. 1044-1047, 2017.

[7] A. Nishanth and C. Vanmathi, "A Cloud Based Natural Hazard Detection and Warning System," vol. V, no. IV, pp. 7-12, 2018. 